Animal Health Research Institute "Immunity".

\title{
DIAGNOSTIC VALUE OF AGAR GEL PRECIPITATION TEST WITH FEATHER TIPS IN DIAGNOSIS OF MAREK'S DISEASE
}

(With 4 Tables and One Figure)

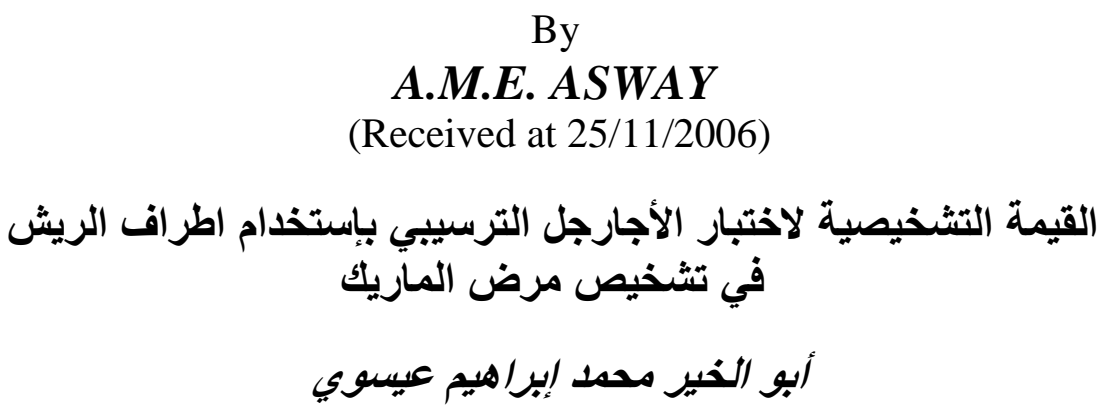

تشخيص مرض الماريك في معظم الحسالات يينى على تـاريخ القطيع و العلامـات الإكلينيكية

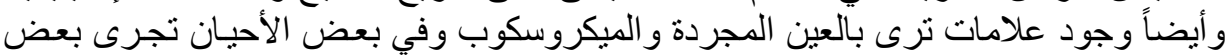

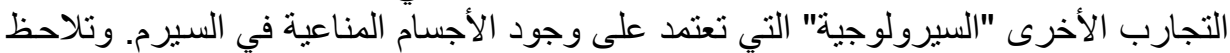

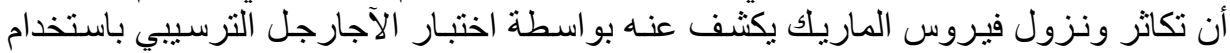

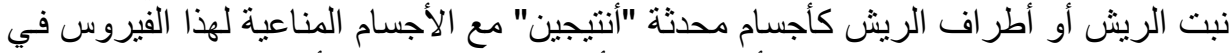

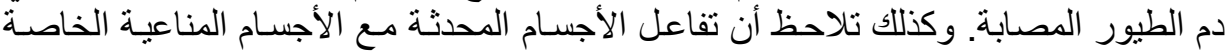

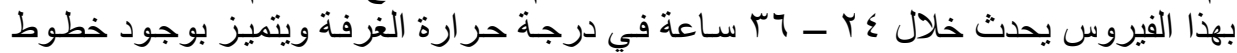
ترسيبية مميزة.

\section{SUMMARY}

In most cases, diagnosis of Marek's disease "MD" can be made on the basis of history, clinical signs and the presence of gross and microscopic lesions (Payne and Venugopal., 2000; Witter and Schat., 2003). However, in certain cases, additional tests e.g. immunohistochemistry using monoclonal antibodies are recommended. Being the replication in and shedding from feather follicle epithelium of complete Marek's disease virus (MDV), simple agar- gel diffusion test is employed, using an homogenate of feather follicles or more simply, the feather tips as antigen against an hyperimmune specific antiserum. The reaction antigen-antibody occurs in 24-36 hours of incubation at room temperature and is characterized by very marked precipitation line.

Key words: Agar gel precipitation test, marek's disease 


\section{INTRODUCTION}

Marek's disease (MD) an economically important lymphoproliferative disease of primarily chickens and a complex neoplastic disease due to herpesvirus.

MD virus (MDV) is classified into 3 serotype $1,2 \& 3$ with all virulent or pathogenic strains placed in serotype 1 . Currently, virulent strains of MDV are classed into 4 pathogens, mild (mMDV), virulent (vMDV), very virulent (vvMDV), and very virulent plus (vv+MDV) (Witter et al., 2003). Lesions of MD can be expressed in one or more of 4 forms, namely neural, visceral, ocular and cutaneous (Payne and Venugopal, 2000; Witter et al., 2003) one of the most interesting aspects of MD has always been the mechanism of transmission.

It was demonstrated that the cells of feather follicle epithelium (FFE) are the sites of greatest maturation, concentration and shedding of MDV (Calnek et al., 1970; Zanella, 1970). Also, non oncogenic MDV and HVT mature in such tissues (Cho, 1977; Witter et al., 1972). Diagnosis of MD has been based for long period above all on macroand microscopic lesions in tissues. After the discovery that FFE is the main site of productive MDV replication, also agar-gel diffusion (AGD) test was get ready, using the homogenate of FFE or the feather tips (FT) as antigen and an hyperimmune antiserum as antibody (Heider et al., 1970; Ronnga-Tabbu and Cho, 1982; Davidson et al., 1986). Successively, finer techniques as dot-blot and polymerase chain reaction (PCR), able to reveal viral DNA in feather pulp have been applied. This last techniques are very sensitive, detecting also very small amounts of virus and would permit not only the differentiation among the 3 serotypes of virus, but also between the oncogenic serotype 1 viruses (Becker et al., 1992; Davidson et al., 1986; Davidson and Barenshtain, 2002). Nevertheless, the differentiation between oncogenic and nononcogenic MDV and HVT resulted possible also with AGD test, because FFE, infected with the last 2 types of virus very rarely or not include positive reaction that is likely due to their relatively low replication and concentration in such tissues (Rannga-Tabbu and Cho, 1982; Zanella et al., 2004).

Recently it has been demonstrated that the feather pulp is considered the most favorable source of subgroup- $\mathbf{J}$ of Avian Leucosis Virus (ALV- J).

The concentration of virus was usually found higher than in other tissues (Sung et al., 2001) and PCR, using DNA from FT, resulted 
more effective for diagnosis of infected chicken (Davidson and Barenshtain, 2002). Nevertheless, no mention has been done on AGD test so far, it could be not able due insufficient concentration of antigen.

The aim of this work is to evaluate the meaning of the results of AGD test with FT, carried out in pullets at any time, but particularly between 12 and 18 weeks of age not only from diagnostic, but also and mainly from prognostic point of view with regard to MD.

\section{MATERIALS and METHODS}

New growing feather from apparently healthy bird were plucked from 3 different parts of each hen. Tips of each feather quill were cut $(5 \mathrm{~mm})$, they cloud be kept in refrigerator or in freezer for weeks or longer.

\section{Agar-gel diffusion test:}

The AGD tests were performed using an agar-gel prepared as described by Davidson et al., (1986). $3 \mathrm{ml}$ of melted agar were overlaid on 76 x $26 \mathrm{~mm}$ slides and solidified. Up to 8 wells, $3 \mathrm{~mm}$ in diameter were cut on each slide. Some (5-10) FT from each bird were inserted aroum each well, 3-4 mm apart. Then the wells were filled with hyperimmune MDV antiserum and refilled 10 minutes later. The reaction was read 24-36 h. postincubation at room temperature. Formation of precipitation line was observed, exhibiting an identity with line of positive control antigen (one every slide).

\section{Viruses:}

\section{Vaccinal viruses:}

MDV LCBS 216/68, attenuated by 75 passages on tissue-culture, Rispens and HVT Fc-126 strains (Zanella and Marchi, 1984) were supplied by ISO, Italy.

\section{Challenge viruses:}

MDV LCBS 212/65, E 107/81, MD-5 strains (Zanella et al., 2004) were supplied by Vaccine and Sera Institute, Abbasia, Cairo.

\section{Experimental trails: \\ Trail 1:}

120 one-day old commercial chicks, divided into 4 groups, were vaccinated I/M with HVT Fc-126 for the $1^{\text {st }}$ group, MDV LCBS 216/68 for the $2^{\text {nd }}$ group (Zanella and Marchi, 1984), or both for the $3^{\text {rd }}$ group, while the $4^{\text {th }}$ group kept as control "unvaccinated". After 10 days the bird of each group were identified with numbered ring and challenged by contact SPF chicks, previously infected with vvMDV (E-107/81) strain. 
At intervals of 2 weeks from challenge, the feathers from birds vaccinated were plucked for AGD test. The birds were controlled for 30 weeks. All birds were necropsid.

\section{Trail 2:}

90 one-day old SPF chicks, divided into 3 groups, were vaccinated I/M with monovalent HVT Fc-126 for the $1^{\text {st }}$ group bivalent MDV LCBS $216 / 68$, for the $2^{\text {nd }}$ group, while the $3^{\text {rd }}$ group kept as control "unvaccinated". After 10 days the birds of each group were identified with numbered ring and challenged $\mathrm{I} / \mathrm{P}$ respectively with LCBS 212/65, E-107/81 or MD-5 strains of MDV (Zanella et al., 2004). At intervals of 2 weeks from challenge, the feathers from number of birds were plucked for AGD test. The birds were controlled for 30 weeks and all were necropised.

\section{RESULTS}

Figure 1: AGD reaction to evidence MD antigen in feather tips. 
Table 1: Detection of MDV antigen in FT of commercial chickens vaccinated as one-day old with HVT or attenuated MDV (LCBS 216/68) or bivalent vaccine via I/P and challenged after 10 days by contact with chickens previously infected with vvMDV E-107/81 isolate

\begin{tabular}{|c|c|c|c|c|c|c|c|c|c|c|c|}
\hline \multirow[t]{4}{*}{ Vaccine } & \multicolumn{9}{|c|}{ AGD with FT at weeks of age } & \multicolumn{2}{|c|}{$\begin{array}{l}\text { MD mortality } \\
\text { or lesions at } \\
30 \text { weeks }\end{array}$} \\
\hline & \multicolumn{9}{|c|}{ With challenge } & & \\
\hline & \multirow{2}{*}{2} & \multirow{2}{*}{4} & \multirow{2}{*}{6} & \multirow{2}{*}{8} & \multirow{2}{*}{10} & \multirow{2}{*}{11} & \multirow{2}{*}{12} & \multicolumn{2}{|c|}{14} & \multirow{2}{*}{ No. } & \multirow{2}{*}{$\%$} \\
\hline & & & & & & & & No & $\%$ & & \\
\hline HVT & $0 / 20$ & $1 / 20$ & $3 / 20$ & $5 / 20$ & $5 / 20$ & $3 / 20$ & $3 / 20$ & $3 / 20$ & 15.0 & $4 / 20$ & 20.00 \\
\hline MDV-1 & $0 / 20$ & $0 / 20$ & $1 / 20$ & $2 / 20$ & $4 / 20$ & $6 / 20$ & $6 / 20$ & $6 / 20$ & 30.0 & $5 / 20$ & 25.0 \\
\hline HVT+MDV 1 & $0 / 20$ & $0 / 20$ & $1 / 20$ & $1 / 20$ & $0 / 20$ & $0 / 20$ & $0 / 20$ & $0 / 20$ & 0.0 & $1 / 20$ & 5.0 \\
\hline Control & $0 / 20$ & $9 / 20$ & $18 / 20$ & $18 / 20$ & $18 / 20$ & $16 / 20$ & $15 / 20$ & $14 / 20$ & 70.0 & $12 / 20$ & 60.0 \\
\hline
\end{tabular}

Table 2: Presence at different time of MDV antigen in FT of SPF chickens vaccinated as one-day old, with HVT or bivalent (HVT + MDV LCBS 216/68) vaccine via I/M and challenged after 10 days with 3 different isolates of MDV via $\mathrm{I} / \mathrm{P}$

\begin{tabular}{|c|c|c|c|c|c|c|c|c|c|c|c|c|}
\hline \multirow{2}{*}{ Isolate for challenge } & \multicolumn{10}{|c|}{ AGD test with FT at weeks after challenge } \\
\cline { 2 - 13 } & 2 & 4 & 6 & 8 & 2 & 4 & 6 & 8 & 2 & 4 & 6 & 8 \\
\hline LCBS 212/65 (v) & 4 & 7 & 3 & 1 & 0 & 5 & 1 & 1 & 6 & 6 & 5 & 5 \\
\hline E-107/8 (vv) & 4 & 9 & 5 & 4 & 0 & 4 & 0 & 0 & 6 & 6 & 6 & 6 \\
\hline MD-5 (vv) & 5 & 7 & 6 & 2 & 2 & 2 & 1 & 0 & 6 & 6 & 6 & 5 \\
\hline
\end{tabular}

N.B. All birds with persisting FT positive died with MD lesion.

Table 3: The percentage of protection and MD immortality or lesions at 30 weeks of age

\begin{tabular}{|c|c|c|c|c|c|}
\hline \multirow{2}{*}{$\begin{array}{c}\text { Isolates for } \\
\text { challenge }\end{array}$} & \multicolumn{2}{|c|}{ Vaccines } & \multirow{2}{*}{ Control } & \multicolumn{2}{|c|}{ Protection \% } \\
\cline { 2 - 3 } \cline { 5 - 6 } & HVT & HVT + MDV & & HVT & HVT + MDV \\
\hline LCBS 212/65 & $3 / 15(20.0)$ & $0 / 15(0)$ & $11 / 15(73.3)$ & 80.0 & 100 \\
\hline E-107/8 & $4 / 15(26.7)$ & $0 / 15(0)$ & $15 / 15(100)$ & 73.3 & 100 \\
\hline MD-5 & $3 / 15(20.0)$ & $1 / 15(6.7)$ & $15 / 15(100)$ & 80.0 & 93.3 \\
\hline
\end{tabular}


Table 4: Relationship between presence of precipitating antigen in FT and mortality due to MD in chickens vaccinated with HVT, presenting early break of immunity

\begin{tabular}{|c|c|c|c|c|c|c|c|c|c|c|c|c|c|c|c|}
\hline \multirow[b]{2}{*}{$\begin{array}{l}\text { Bird } \\
\text { No. }\end{array}$} & \multicolumn{13}{|c|}{ Age of feather sampling (in weeks) } & \multicolumn{2}{|c|}{ Results } \\
\hline & 3 & 5 & 7 & 9 & 11 & 13 & 15 & 17 & 18 & 20 & 22 & 24 & 26 & 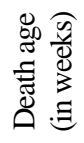 & $\frac{\sqrt[5]{\frac{0}{3}}}{\stackrel{3}{2}}$ \\
\hline 1 & + & + & + & + & + & & & & & & & & & 12 & $\bar{G}$ \\
\hline 2 & + & + & + & + & + & & & & & & & & & 12 & $\mathrm{G}$ \\
\hline 3 & + & + & + & + & + & + & & & & & & & & 13 & $\mathrm{G}$ \\
\hline 4 & - & - & - & \multicolumn{3}{|c|}{ Paralysis } & & & & & & & & 13 & $\mathrm{~N}$ \\
\hline 5 & - & - & - & \multicolumn{3}{|c|}{ Paralysis } & & & & & & & & 13 & $\mathrm{~N}$ \\
\hline 6 & - & - & + & + & + & + & - & & & & & & & 13 & $\mathrm{G}$ \\
\hline 7 & + & + & + & + & + & + & + & & & & & & & 15 & $\mathrm{G}$ \\
\hline 8 & + & + & + & + & + & + & - & & & & & & & 15 & $\mathrm{G}$ \\
\hline 9 & + & + & + & + & + & + & + & & & & & & & 15 & $\mathrm{G}$ \\
\hline 10 & + & + & + & + & + & + & + & & & & & & & 16 & $\bar{G}$ \\
\hline 11 & + & + & + & + & + & + & + & & & & & & & 16 & $\mathrm{G}$ \\
\hline 12 & + & + & + & + & + & + & + & + & + & + & - & - & - & 20 & $\mathrm{G}$ \\
\hline 13 & + & + & + & + & + & + & + & + & + & + & + & - & - & 22 & $\bar{G}$ \\
\hline 14 & + & + & + & + & + & + & + & + & + & + & + & - & - & 22 & $\mathrm{G}$ \\
\hline 15 & + & \pm & + & - & - & - & - & - & - & - & - & - & - & - & $\mathrm{G}$ \\
\hline 16 & \pm & - & - & - & - & - & - & - & - & - & - & - & - & - & $\mathrm{G}$ \\
\hline 17 & - & - & - & - & - & - & - & - & - & - & - & - & - & - & $\mathrm{G}$ \\
\hline 18 & - & - & - & - & - & - & - & - & - & - & - & - & - & - & $\mathrm{G}$ \\
\hline $19 / 30$ & - & - & - & - & - & - & - & - & - & - & - & - & - & - & $\mathrm{G}$ \\
\hline
\end{tabular}

G: Generalized.

$\mathrm{N}$ : Nerves.

\section{DISCUSSION}

The positive reaction by AGD test was characterized by Marked, usually continous precipitation line between antigen (FT) and antiserum (Figure 1).

In trail 1, with exposure to vvMDV by contact, the percentage of positivity to AGD test at 11 weeks of age resulted in the different groups, rather similar to the incidence of MD at 30 weeks of age (Table $1)$.

In trail 2, part of vaccinated birds resulted temporarily positive to AGD test in the $1^{\text {st }}$ week after challenge via $\mathrm{I} / \mathrm{P}$ with 3 different isolates of v- or vvMDV, becoming negative after 8 weeks in case of bivalent vaccine such effect resulted less evident in case of HVT vaccine (Tables $2 \& 3$ ) only for few birds the reaction resulted partial or doutful, but mainly to disappear. Only in 2 birds it was possible to observe recovery 
after many weeks of malaise and residual vestige of positive reaction, regression of lesions in proventriculus was observed. The FT of birds (about 10) affected only by peripheral neuropathy resulted always negative.

It has been demonstrated that there is significant relationship between the percentage of positively by AGD test and the cumulative MD mortality, at least up to 50 weeks of life, sometimes to the end of period. The result of some representative trails are reported in Table (4).

The testing of FT for MDV antigen by AGD test may be very simple and useful tool for monitoring oncogenic MDV in flock of chickens, also because of very rare or no occurrence of detectable antigens in FT of chickens infected with non-oncogenic MDV or HVT, more likely due to lower replication of these last viruses in FFE (Rannga-Tabbu and Cho, 1982; Zanella et al., 2004).

High percentage of chicken inoculated with bivalent vaccine (HVT + MDV serovar 1) show negative or temporary and weak positive AGD reaction after challenge, also with vvMDV strains. Such effect was considerably less evident in case of vaccination only with HVT.

Nearly, all birds showing persistently AGD positive reaction were doomed to die, recovery was observed very seldom. The FT of birds affected only by neural lesions, probably related to MD were always negative (at least 30 observation), the reason of that is unknown. However, a syndrome with enlargement of nerves of peripheral neuropathy has been recently reported, but almost exclusively in white leghorn pullets, probably of immunomediate origin (Bacon et al., 2001; Massi et al., 2003; Rampin et al., 2003).

On the contrary, the use of dot-blot and PCR tests would allow only to point out the presence of virus, which persists also in the healthy birds, they have some diagnostic, but no prognostic value.

In conclusion, the use of AGD test with FT deserves particular attention for simple, rapid, accurate and not expensive diagnosis, feasible in all laboratories, but also for its sure prognostic value on future MD incidence in flock of chickens. So, it could be of value, at least indicative if not legal, in the sale of pullets, rather frequent practice in several countries.

\section{REFERENCES}

Bacon, L.D.; Witter, R.L. and Silva, R.F. (2001): Characterization and experimental reproduction of peripheral neuropathy in white leghorn chickens. Avian Pathology, 30: 487-499. 
Becker, Y.; Asher, Y.; Tabor, E.; Davidson, I.; Malkinson, M. and Weisman, Y. (1992): Polymerase chain reaction for differentiation between pathogenic and non pathogenic serotype 1 Marek's disease viruses (MDV) and vaccine virus of MDV serotype 2 and 3. Journal of Virology Methods, 40: 307322.

Calnek, B.W.; Alexander, A.M. and Kahn, D.E. (1970): Feather follicle epithelium: a source of enveloped and infection cell-free herpesvirus from Marek's disease. Avian Diseases, 14: 219233.

Cho, B.R. (1977): Dual virus maturation of both pathogenic and a pathogenic Marek's disease herpes-virus (MDHV) in feather follicles of dually infected chickens. Avian Disease, 21: 501507.

Davidson, I. and Barenshtain, R. (2002): The feather tips of commercial chickens are a favorable source of DNA for the amplification of Marek's disease virus and avian leucosis virus subgroup. J. Avian Pathology, 31: 237-240.

Davidson, I.; Maray, T.; Malkinson, M. and Becker Y. (1986): Detection of Marek's disease virus antigens and DNA in feather from infected chickens. J.V. Meth., 13: 234-244.

Heider, S.A.; Laper, R.F. and Kenzy, S.G. (1970): Use of feather in a gel precipitation test for Marek's disease. Poultry Science, 49: 1654-1657.

Massi, P.; Leonelli, R.; Gelmetti, D.; Fiorentini, L. and Tosi, G. (2003): Peripheral Neuropathy Syndrome (PNS) in white layer chickens. Large Animal. Review, 9, (6), 99-100.

Payne, L.N. and Venugopal, K. (2000): Neoplastic Diseases: Marek's disease, avian leukosis and Reticuloendotheliosis. Rev. Sci. Tech. Off. Jnt. Epiz. 19: 545-564.

Rampin, T.; Manarolla, G.; Sironi, G.; Gvidarini, C. and Motta, C. (2003): Field cases of peripheral neuropathy in layer pullets. Large Animals. Review, 9, (6), 69-70.

Ronnga-Tabbu, C. and Cho, B.R. (1982): Marek's Disease Virus (MDV) antigens in feather follicle epithelium: difference between oncogenic and non-oncogenic MDV. Avian Diseases, 26: 907917.

Sung, H.W.; Reddy, S.M. and Fadly, A.M. (2001): High virus titre in feather pulp of chickens infected with subgroup $\mathrm{J}$ avian leucosis virus. Avian Diseases, 47: 281-286. 
Witter, R.L.; Nazerian, E. and Soloman, J.J. (1972): Studies on the vivo replication of turkey herpesvirus. Journal of National Cancer Institute, 4: 1121-1130.

Witter, R.L. and Schat, K.A. (2003): Marek's disease. In: Y. M. Saif, H.I. Barnes, A.M. Fadly, I.R. McDougald and D.E. Swayne (Eds.) Diseases of Poultry, $11^{\text {th }}$ Ed. pp. 407-465. Lowa State University Press, Ames, Lowa.

Zanella, A. (1970): Marek's Disease: transmission of infected by filtrate of feather follicles. Archivio Veterinario Italiano, 2: 229-234.

Zanella, A. and Marchi, R. (1984): Marek's Disease: survey on vaccine failures and remedies. Clinica Veterinarie, 107: 217-229.

Zanella, A.; Marchi, R. and Rosi, P. (2004): Malattia di Marek: test di agar-gel diffusione con le penne come mezzo diagnostico prognostico. Clinica Veterinaria, 107: 141-147. 